\title{
INTERAÇÕES ENTRE ENFERMEIRAS E PAIS DE CRIANÇAS HOSPITALIZADAS
}

\author{
Edelia del Pilar Neira Huerta*
}

NEIRA HUERTA, E. del P. Interaçס̄es entre enfermeiras e pais de crianças hospitalizadas. Rev. Esc. Enf. USP, São Paulo, 19(1): 81-93, 1985.

Com a finalidade de oferecer subsidios às enfermeiras de unidades pediaitricas e utilizando a observação como método, a autora procura analisar e comentar as interaçбes que ocorrem entre enfermeiras e pais de crianças hospitalizadas em diferentes situaf̧zes que săo comuns à hospitalizaçăo de crianģas.

\section{INTRODUÇÃO}

$\mathrm{Na}$ literatura são vários os autores que enfatizam os benefícios que a presença dos pais junto ao filho hospitalizado têm, tanto para a criança, como para os próprios pais. Sua presença no hospital constitui o método mais efetivo para reduzir os traumas psicológicos e emocionais da hospitalização na criança, e, permanecendo junto a seu filho no hospital, os pais têm a oportunidade de sentir que ajudam de uma maneira construtiva na recuperação do filho, o que provoca neles sentimentos de competenicia e realização (BOLWBY ${ }^{3}$, ROBERTSON ${ }^{21}$, PRUGH et alii ${ }^{20}$, NOLAN $^{19}$, MacCARTHY ${ }^{14}$, HARDGROVE \& RUTLEDGE ${ }^{12}$ entre outros).

Alguns autores como NOLAN ${ }^{19}$, WOFFINDIM ${ }^{27}$, VERMILION et alii' ${ }^{25}$, VAN DER SHYFF ${ }^{2}$ e MARLOW ${ }^{17}$ apontam as múltiplas vantagens que a permanência dos pais junto ao filho doente no hospital representam para a equipe hospitalar. Entre essas vantagens, esses mesmos autores mencionam as excelentes oportunidades para detectar problemas no relacionamento pais-criança, relação esta sujeita à intervenção da enfermeira; para observar e avaliar as atitudes, habilidades e técnicas dos pais; para desenvolver habilidades de comunicação e ensino, bem como uma excelente oportunidade para identificar as necessidades da criança e as maneiras mais adequadas de atendê-las. Mac CARTHY ${ }^{14}$ e VERMILION et alii ${ }^{25}$, comentam ainda que, a per-

- Enfermeira. Mestre em Enfermagem. Professor Assistente do Departamento Matemo-Infantil e Psiquiátrica da Escola de Enformagem da USP - disciplina Enfermagem Pediátrica. 
manência da mãe junto ao filho hospitalizado reduz a incidência de infecçð̃es cruzadas devido a que a criança é manipulada por um número significativamente menor de pessoas.

No entanto, apesar dos benefícios e vantagens apontados na literatura, apenas a presença dos pais junto à criança hospitalizada, não implica na sua obtenção de tais benef́́cios.

Segundo HARRIS ${ }^{13}$, BARBOSA ${ }^{1}$ e SCOFIELD ${ }^{23}$, entre outros, a própria situação de hospitalização da criança é altamente estressante para os pais, os quais reagem com diferentes graus de ansiedade. Os mesmos autores comentam que, quando não é oferecido aos pais o apoio e ajuda que necessitam, eles entram em pânico, ficando, dessa forma, impossibilitada a obtenção de todos os benefícios e vantagens anteriormente referidos.

MAHAFFY ${ }^{16}$ e FAGIN ${ }^{8}$ opinam que esses benefícios e vantagens só podem ser obtidos quando os pais são assistidos e encorajados a participar dos cuidados ao filho durante a internação da criança, assistência esta que deve ser iniciada no momento da admissão ao hospital e constituir-se num processo contínuo até a alta hospitalar.

Das considerações acima deduz-se a necessidade de um profissional da equipe hospitalar interagir efetivamente com os pais de crianças hospitalizadas, ou, dito de outra maneira, a necessidade desses pais experimentarem um relacionamento significativo com um profissional da equipe hospitalar.

Acreditando ser a enfermeira um profissional qualificado para estabelecer e manter esse relacionamento e, com a finalidade de oferecer às enfermeiras de unidades pediátricas subsídios que lhes permitam melhorar sua assistência a pais de crianças hospitalizadas, me propus, para este trabalho, o seguinte objetivo: analisar e comentar as interações que ocorrem entre enfermeiras e pais de crianças hospitalizadas em diferentes situaçðes que são comuns à hospitalização de crianças.

\section{METODOLOGIA}

Para atender ao objetivo proposto, escolheu-se como método a observação e como local uma unidade que apresenta sistema de internação conjunta; isto por acreditar que numa unidade com essa característica, as enfermeiras estejam melhor preparadas para trabalhar junto aos pais de crianças internadas.

Considerando que determinadas situaçð̃es fazem parte das vivências, tanto de enfermeiras quanto de pais de crianças hospitalizadas, selecionou-se as seguintes situaçð̃es a serem observadas: admissão da criança à unidade hospitalar, execução de um procedimento traumático na criança hospitalizada, passagem de plantão da equipe de enfermagem na unidade e morte na unidade pediátrica. 
Vale a pena comentar que, apesar de se considerar a alta hospitalar como uma dessas vivências, por acreditar que as interações que nela poderiam ocorrer seriam apenas o resultado de um relacionamento anterior, durante a hospitalização da criança, ela não foi incluída.

\section{DESCRIÇÃO E ANÁLISE DAS SITUAÇÕES OBSERVADAS}

Situação 1: Admissão da criança à unidade hospitalar

A enfermeira $M$. foi avisada pelo interfone de que uma criança seria admitida na clínica (vinda do Pronto-Socorro). $O$ pai, de mãos dadas com a criança, chega à unidade, procura pela enfermeira.

enfermeira : "Venha comigo".

Ambos sentam-se ao lado do posto de enfermagem, um ao lado do outro, criança, no colo do pai, chupando um pirulito, de costas para a enfermeira. São $16 \mathrm{~h} 45 \mathrm{~m}$. O ambiente não é propriamente uma sala, e sim uma prolongação lateral do corredor da unidade onde existe uma mesa com dez cadeiras em espaço reduzido.

enfermeira : "E a mãe da criança?"

pai : "Ela ficou lá embaixo com o outro de um ano no colo".

enfermeira : "Quem fica mais tempo com ele?"

pai : "A mãe. .."

enfermeira : "Quando começou a inchar?"

pai : "Faz quatro dias. .."

enfermeira : "Os pés também?"

pai : "O corpo inteiro."

enfermeira : "É a primeira internação dele?"

pai : "Quando novinho ficou três meses no hospital, teve miningite..."

enfermeira : "E o xixi dele?"

pai : "Não está muito bem; está fazendo pouco e amarelinho. .."

enfermeira : "E o cocô?"

pai : "Ele faz duas vezes por dia. .."

Aproxima-se uma atendente de enfermagem, coloca termômetro e verbaliza "Segura com o braço" retirando-se a seguir. A criança começa a choramingar e a olhar em redor assustada.

enfermeira : "Ele não está acostumado a ficar sozinho?"

pai : "Não".

enfermeira : "E a comida?"

pai : "Ele come de tudo, mas agora não está querendo comer. . ."

enfermeira : "Ele faz xixi no vaso?"

pai : "Sim".

enfermeira : "Ele fala de tudo?" 
pai :"Fala!"

enfermeira :"E chupeta. . . ele usa?"

pai : "Não, não usa".

enfermeira : "Escova os dentes?"

pai : "Sim".

enfermeira : "Trouxe a escova?"

pai : "Não, não sabia que ele ia ficar internado. .."

enfermeira : "Se ele tem algum brinquedo que goste, pode trazer, viu?"

O pai acena com a cabeça. Um grupo de alunos de medicina, em número aproximado de 10, todos falando, se aproximam. Um aluna do grupo pergunta: "É esta a internação?" A enfermeira responde "É!"

A enfermeira retoma a conversa com o pai: "Aqui tem visita todo dia das quatorze às dezesseis horas. Toda quinta-feira d tarde é feita reuniāo de pais com a equipe multiprofissional. É bom vocês assistirem para saber de tudo que está acontecendo. Aqui as crianças têm diferentes doenças e o médico fala dos problemas de doença. Tem psicólogo também. . . Algum outro problema com a criança?"

A atendente se aproxima, retira o termômetro, sem nada dizer e retira-se do local. A criança recomeça a choramingar.

pai : "Ele é muito apegado com a gente. Vai ser o maior choro aí. .." enfermeira : "Alguma coisa que o senhor queira perguntar?. . . Eu sou M., enfermeira da tarde... O senhor já sabe que a visita é das quatorze às dezesseis horas. Sobre exames você pergunta ao médico da tarde; sobre alimentação à nutricionista; se é um problema social fala com a assistente social. . . Algum outro problema que o senhor queira comentar?"

A atendente se aproxima, pega o braço direito da criança e tenta colocar pulseira de identificação; nada diz, a enfermeira também não. A pulseira ficou curta. O pai fala para a criança: "Puxa, já acabou o pirulito!"

A enfermeira levanta-se, fica em pé junto ao balcão, de costas para o pai. São $16 \mathrm{~h} 53 \mathrm{~m}$. O pai permanece de pé, perto da enfermeira, de mãos dadas com a criança. A atendente retorna com uma nova pulseira e, enquanto a coloca, verbaliza: "Não precisa chorar, isto aqui não dói nada". Em seguida se dirige ao pai: "Ele pede para fazer xixi ou ainda usa fraldas?" $O$ pai responde: "Ele faz sozinho; à noite ele dorme com fralda, mas não a molha". A enfermeira permanece no balcão, fazendo pedido de roupas para a unidade pelo interfone.

A atendente diz à criança: "Vamos tomar banho". Enquanto a atendente dá banho na criança e verifica seu peso, o pai permanece em pé na porta da enfermaria. Completados os procedimentos, a atendente sai ao corredor; pai e criança saem atrás dela, permanecendo perto do posto de enfermagem, com 
expressão de estarem aguardando alguma coisa acontecer, até que o pai é abordado pela aluna de medicina antes mencionada, que solicita conversar com ele, guiando-o a seguir a uma sala pequena e privativa.

$O$ relatório de enfermagem está pronto. Nele consta o nome da criança, A., leito e número de registro. $\mathrm{Na}$ coluna destinada às observações foi registrado o seguinte:

$16 \mathrm{~h} 50 \mathrm{~m}$ Foi admitido na Patologia Geral com GNDA. Peso $16.200 \mathrm{~g}$; temperatura: $36^{\circ} \mathrm{C}$, criança veio do Pronto Socorro acompanhada pelo pai. Refere que há 4 dias começou a edemaciar o corpo todo. Está alimentando-se pouco; sem febre. Está urinando e evacuando normalmente. Criança tem controle esfincteriano e vesical; não faz uso de chupeta. Criança nunca ficou sozinha. Pai refere que a mãe não poderá ficar porque tem um filho de 1 ano. Criança de difícil adaptação segundo o pai. Teve meningite aos 3 meses. $\mathbf{M}$.

Em seguida a esta anotação encontra-se uma outra, com letra diferente, que diz:

Foi dado banho geral; criança em boas condiçðes de higiene; foi identificado.

$\mathrm{Na}$ situação acima descrita constata-se que: a entrevista foi realizada num ambiente físico inadequado; a enfermeira se apresentou tardiamente ao pai de A., sem dar a conhecer suas funçðes específicas na unidade; a enfermeira não indagou o nome do pai, limitando-se a formular perguntas impessoais ou a chamá-lo de 'senhor'; e que, durante a entrevista não foram utilizadas técnicas de comunicaçăo apropriadas, sendo empregadas perguntas dirigidas e mudando-se constantemente o centro da comunicação.

WHALEY \& WONG ${ }^{20}$ apontam como fatores que favorecem a comunicação com os pais durante a entrevista na admissão da criança ao hospital, a utilização de um ambiente físico agradável, não ameaçador, que assegure o maior grau de privacidade possível; chamar os pais pelo seu nome junto com a apresentação adequada da enfermeira, ou seja, dar a conhecer seu nome, bem como as suas funçб̃es dentro da unidade, medida esta que, segundo as autoras, permite comunicar respeito e interesse pessoal; e, a utilização de técnicas de comunicação e de perguntas abertas que estimulem a descrição.

Para a comunicação com os pais, WHALEY \& WONG ${ }^{26}$ recomendam, entre outras, as seguintes técnicas: ouvir, estimular a falar, utilizar adequadamente o silêncio, prover aceitação e evitar bloqueios na comunicação. As autoras afirmam ainda que, a comunicação com os pais pode ser bloqueada ao utilizar perguntas dirigidas, que eliminam a expressão de sentimentos; mudar deliberadamente o centro da comunicação; tirar conclusðes precipitadas e empregar uma linguagem diferente daquela utilizada pelos pais. 
$\mathrm{Na}$ admissão de $\mathrm{A}$., antes descrita, verifica-se que, apesar do conteúdo de algumas verbalizações do pai de A., como por exemplo: "Ele é muito apegado com a gente; vai ser o maior choro aí. ..", a enfermeira não o ajudou a expressar seus sentimentos e preocupaçōes pela internação do filho, e conseqüentemente, esses não foram identificados nem compreendidos.

Segundo BLAKE et aliii $^{2}$, na admissão da criança ao hospital devemos, antes de mais nada, dar apoio emocional, tanto à criança como a seus pais, sendo que, para a autora, o princípio básico do apoio emocional efetivo é a compreensão dos sentimentos do outro junto com a capacidade de responder a eles de maneira a fortalecer as reservas do cliente para superar suas dificuldades.

MAHAFFY ${ }^{15}$ e MARLOW ${ }^{17}$ enfatizam a importância de identificar as necessidades dos pais e de permitir-lhes expressar seus sentimentos e preocupaçбes pela doença e hospitalização do filho desde o momento da internação, apontando a entrevista com os pais, na admissão da criança no hospital, como um valioso instrumento a ser utilizado.

A respeito da entrevista com os pais, MORAES ${ }^{18}$ afirma que a preocupação primeira é a de ouví-los e identificar seus sentimentos e preocupaçōes, recomendando para isto a entrevista não diretiva.

$\mathrm{Na}$ situação descrita verifica-se, também, que a enfermeira não mostrou ao pai de $\mathrm{A}$. os benefícios que a presença da mãe, dele próprio ou de um parente próximo teria para a criança, decidindo por ele, sem consultá-lo, que a mãe de A. não poderia permanecer junto ao filho doente durante a hospitalização.

FAGIN $^{8}$ enfatiza que os pais de crianças pequenas devem ser encorajados a permanecer com seus filhos no hospital, afirmando que, quando os pais são claramente informados e esclarecidos em relação aos benefícios que sua presença no hospital terá para a criança, a maioria deles decidirá ficar.

MORAES ${ }^{18}$ opina ser necessário confiar na capacidade dos pais de sentir, pensar e agir na resolução de seus problemas, particularmente quando em benefício do próprio filho. A autora afirma ainda que o papel da enfermeira concentra-se em reforçar essa capacidade dos pais.

Constata-se, também, na situação acima descrita, que a enfermeira orientou o pai de A. em relação aos horários de visita da unidade, deu informações a respeito da reunião semanal que a equipe profissional realiza com os pais das crianças internadas na unidade, bem como em relação aos diferentes profissionais que poderiam esclarecer suas dúvidas ou auxiliá-lo na resolução de seus problemas, profissionais estes entre os quais ela própria não se incluiu. Nessa orientação a enfermeira empregou termos técnicos talvez desconhecidos pelo pai. 
$\mathrm{Na}$ situação descrita constata-se, ainda, que a atendente de enfermagem não encorajou o pai de A. a participar dos cuidados a seu filho na admissão, interagindo escassamente com ele; comportamentos estes que se apresentam como um reflexo da atitude da enfermeira em relação ao pai de $\mathbf{A}$.

MARLOW ${ }^{17}$, BLAKE et alii $^{2}$ e WHALEY \& WONG ${ }^{26}$ recomendam que, no processo de admissão da criança ao hospital, os pais proporcionem à criança todos os cuidados que eles sejam capazes de dar, citando, entre eles, banho, alimentação e controle de temperatura. Segundo as autoras, esta medida, além de favorecer a adaptação da criança ao meio hospitalar e de diminuir a ansiedade dos pais, oferece à enfermeira a oportunidade de identificar algumas necessidades da criança e a maneira como estas são atendidas, bem como de começar a avaliar as habilidades dos pais no cuidado do filhó, identificando, dessa maneira, necessidades de orientação e ensino.

Por todo o anteriormente exposto, compreende-se que o relatório da enfermeira seja apenas o reflexo da não utilização de técnicas adequadas para uma avaliação completa tanto da criança como de seu pai.

Verifica-se, assim, que as interações enfermeira-pai na situação descrita, não foram efetivas $e$, conseqüentemente, não foi estabelecido um relacionamento significativo, essencial à assistência que o pai de A. necessitava; seus sentimentos e preocupaçð̄es nฮ̃o foram identificados e, portanto, não houve uma intervenção, por parte da enfermeira, que proporcionasse ao pai de A. 0 apoio e a ajuda que ele precisava.

\section{Situação 2: Execução de um procedimento traumático na criança hospitaliza- $d a$}

D., menina de 2 anos, filha única, com diagnóstico de hepatomegalia a esclarecer, internada na unidade por um período superior a vinte dias - periodo em que fora acompanhada constantemente por sua mãe, e durante o qual ainda não fora possível elucidar a causa da sintomatologia motivo da internação - apresenta-se severamente depauperada e muito abatida; devido à recusa de alimentação, indicaram-lhe sonda nasogástrica (SNG).

Duas enfermeiras aproximam-se do berço de D. para dar cumprimento à indicação médica. Sem nada verbalizarem iniciam a instalação de SNG em D. Enquanto executam o procedimento, D. chora debilmente olhando para sua mãe, que permanece sentada numa banqueta ao lado do berço da criança, tronco inclinado para a frente, mãos cruzadas no colo e olhar perdido.

Durante o procedimento não houve comunicação verbal entre enfermeiras e a mãe, nem entre enfermeiras e a criança. Uma vez completado o procedimento e após a saída das enfermeiras, abordei a mãe de D.; ela não sabia o que estava acontecendo, nem porquê; estava muito preocupada com o estado de sua filha e sentia medo em relação ao tipo de doença da criança, chegando a verbalizar medo de sua filha vir a falecer. 
$\mathrm{Na}$ situação acima descrita constata-se que, nem antes, durante ou após a execução do procedimento houve interaçð̋es entre as enfermeiras e a mãe da criança e, conseqüentemente, não the foi oferecida oportunidade para expressar seus sentimentos, preocupações e dúvidas em relação à filha e ao procedimento executado; tampouco foi verificado o que ela sabia ou necessitava saber a respeito da introdução de SNG e, a mãe de D. não foi encorajada a dar apoio e segurança à fillha. Verifica-se, portanto, que nada foi feito para diminuir a ansiedade da mãe.

Por outro lado, a mãe de D., que permanecia na unidade por vários dias, não apresentou às enfermeiras suas dúvidas e preocupaçбes. Os comportamentos, tanto das enfermeiras quanto da mãe, indicam ausência de relacionamento baseado numa relação de confiança, sem o qual nenhuma assistência à mãe poderia ser completa ou efetiva.

Em relação à ansiedade dos pais no hospital, BRIGHT $^{4}$ opina que a ansiedade incapacita a mae para perceber as necessidades do filho, prejudicando, desse modo, sua capacidade para se relacionar com ele e com os membros da equipe hospitalar. A autora acrescenta que essa ansiedade é transmitida da mãe para o filho.

BRIGHT $^{5}$ propõe passos sistematizados para diminuir a ansiedade dos pais. $O$ primeiro refere-se ao reconhecimento das manifestaçóes de ansiedade, as que, segundo a autora, se caracterizam por alteraçðes fisiológicas e do comportamento. Para BRIGHT ${ }^{5}$, uma pessoa excessivamente ansiosa pode ficar imobilizada, perder a espontaneidade e flexibilidade, particularmente nas interaçסes com outros, podendo sua postura chegar a ser rígida.

O segundo passo proposto por BRIGHT ${ }^{5}$ trata da identificaçăo das causas da ansiedade dos pais. A esse respeito, FREIBERG ${ }^{11}$, de seu estudo das opiniőes de mães que acompanharam seus filhos no hospital, concluiu, como causas entre outras: a falta de informações a respeito do diagnóstico, tratamento e procedimentos; medo do tratamento e procedimentos; temor em relação à recuperação da criança e medo da criança ter uma doença fatal.

Como terceiro passo para diminuir a ansiedade dos pais, BRIGHT $^{5}$ indica açōes de enfermagem conforme a origem da ansiedade, sugerindo, entre elas, aceitação da ansiedade dos pais e de suas causas; orientação sobre as causas da doença e sobre os cuidados e procedimentos; encorajar e dar tempo aos pais de maneira a permitir-lhes formular perguntas e apresentar suas dúvidas, e, envolvimento da mãe no cuidado do filho, sendo que esta última ação é apontada pela referida autora como o melhor mecanismo de controle da ansiedade da mãe.

\section{Situação 3: Passagem de plantão da equipe de enfermagem na unidade}

Durante uma conversa com dona $L$. que permanecia junto a sua filha $E$. - criança de 5 anos, submetida horas antes a esplenoportografia, ainda sob 
os efeitos da anestesia e com infusão intravenosa instalada no membro superior direito - subitamente ela interrompe suas verbalizaçðes e, olhando em direção à porta da enfermaria, levanta-se da banqueta. Olhei nessa direção e vi a enfermeira passando plantão com a equipe de enfermagem. Nesse momento pude perceber, também, que a outra mãe, que acompanhava seu filho na mesma enfermaria, tinha saído do local. A enfermeira sorriu para mim, retirando-se a seguir junto com sua equipe. De imediato, a mãe deu continuidade a suas verbalizaçбes, voltando a sentar-se.

Nossa conversa prolongou-se por mais meia hora; nesse tempo não foi passado plantão da equipe de enfermagem ao lado de E., de sua mãe, nem da outra criança da enfermaria. Nessa meia hora houve visita médica na enfermaria, ocasião que dona L. aproveitou para expressar seus temores em relação ao estado da criança e para formular suas dúvidas em relação ao exame que fora feito.

Tanto o comportamento da enfermeira quanto o comportamento de dona L. surpreenderam-me. Mais tarde, revendo o folheto que é entregue na admissão às mães que permanecem na unidade, pude compreender a causa desses comportamentos; no folheto consta: "Quando estiver na enfermaria: . . . saia para o corredor durante a passagem de plantð̃o".

Na situação acima descrita constata-se que, durante a passagem de plantão da equipe de enfermagem, não houve interaçōes entre a enfermeira e as mães acompanhantes, demonstrando dona $L$. comportamentos que indicam submissão à enfermeira. Através desses fatos percebe-se ausência de um relacionamento significativo enfermeira-mãe, e que as enfermeiras da unidade em que a situação foi observada não percebem as mães acompanhantes como participantes plenos e essenciais no cuidado e recuperação das crianças. Conseqüentemente, as enfermeiras não aproveitam a passagem de plantão como uma ocasião para uma interação significativa com as mães, planejando junto com ela alguns cuidados para as crianças, bem como favorecendo sua participação ativa no cuidado de seus filhos.

MARLOW ${ }^{17}$, além de enfatizar que as enfermeiras devem promover relaçōes de confiança com os pais de crianças hospitalizadas, afirma que elas devem elaborar junto com os pais o plano de cuidados para a criança, partilhando com eles conhecimentos e valorizando as habilidades dos pais para resolver qualquer problema que possa surgir no cuidado da criança.

FAGIN ${ }^{9}$ comenta que, planejar os cuidados de enfermagem junto com os pais e dar as orientaçð̋es necessárias sobre aspectos desses cuidados é um procedimento que inicialmente consumirá mais tempo do que a prática tradicional, mas, acrescenta a autora, representa um investimento que, mais tarde, deixará a equipe de enfermagem consideravelmente mais livre.

Durante a passagem de plantão a mãe pode fornecer valiosas informaçðes em relação a comportamentos da criança durante a alimentação, sono, higie- 
ne, recreação, etc.; a respeito das formas habituais de atender as necessidades da criança, e, em relação à ocorrência de problemas, tanto nas atividades da vida diária da criança como em relação ao tratamento instituído. Estas informações, quando consideradas e valorizadas pela enfermeira, contribuem, não apenas a um melhor cuidado da criança, mas também a uma relação enfermeira-mãe significativa.

A passagem de plantão representa, também, uma oportunidade para a enfermeira desempenhar algumas das responsabilidades inerentes a seu papel junto à mãe acompanhante. Numerosos autores, FAGIN ${ }^{8}$, MAHAFFY $^{16}$ e MARLOW ${ }^{17}$ entre outros, concordam que esse papel consiste em dar o apoio que a mãe necessita para continuar sendo mãe no hospital.

Algumas responsabilidades inerentes a esse papel da enfermeira são: estabelecer e manter uma relação profunda, calorosa e de confiança com a mae $\left(\right.$ EYRES $^{7}$, FAGIN $^{8}$, MARLOW ${ }^{17}$ ); identificar constantemente e atender as necessidades emocionais e físicas da mãe (MAHAFFY ${ }^{16}$, MARLOW ${ }^{17}$, BRIGHT $^{4}$ ); promover e manter o comportamento materno, encorajando a mãe a participar do cuidado do filho (ROY ${ }^{22}$, Mac CARTHY ${ }^{14}$ ); avaliar as habilidades e técnicas da mãe no cuidado do fillho, para assim identificar necessidades de orientação e ensino (MARLOW ${ }^{17}$, WHALEY \& WONG ${ }^{26}$ ); orientar a mãe para prestar cuidados adequados ao filho, durante e após a hospitalização (Mac CARTHY ${ }^{34}$, FAGIN ${ }^{8}$, WHALEY \& WONG $^{26}$ ); antecipar e interpretar para a mãe os procedimentos de diagnóstico e tratamento e esclarecer suas dúvidas $\left(F A\right.$ FIN $\left.^{8}, \mathrm{EYRES}^{7}, \mathrm{ROY}^{22}\right)$; e, ensinar para a saúde, ou seja, ensinar hábitos sanitários, noçð̋es de enfermidades e sua prevenção, etc. (WHALEY \& WONG ${ }^{26}$ ).

\section{Situação 4: Morte na unidade pediátrica}

C., menino de 9 anos, portador de leucemia monocítica aguda, entra em parada cardiorespiratória; seu pai é imediatamente solicitado a sair da sala. Três enfermeiras auxiliam nos procedimentos de reanimação e de instalação de aparelho de ventilação. Enquanto a porta da sala permanece fechada, o pai de C. permanece no corredor, percorrendo-o incessantemente de um a outro extremo, com as mãos fortemente apertadas nas costas.

C. falece; a porta da sala é novamente aberta. Um médico da equipe comunica ao pai de C.: "Sinto muito, fizemos tudo quanto era possível", retirando-se logo após. As enfermeiras começam o preparo do corpo de C. e a retirar aparelhos e materiais da sala. Nos seus rostos pareceu-me observar sofrimento e, pela sua atividade, pude reconhecer ansiedade nelas.

O pai, após ter recebido a notícia, senta-se numa poltrona do lado de fora da sala, permanecendo rígido, olhar perdido por longos minutos. Compreendendo seus sentimentos ante a perda do filho, muito emocionada, me aproximei dele para prestar-lhe apoio e ajudá-lo a enfrentar a realidade. 
A descrição acima permite ver que, nessa situação de grande estresse e sofrimento para o pai de C., e, portanto, de grande necessidade de apoio e consolo, as enfermeiras se mantiveram afastadas, não interagindo com o pai de C. e executando técnicas manuais que poderiam ter sido delegadas.

FOND $^{10}$ afirma que a morte é a experiência mais ameaçadora que as crianças, suas famílias e a equipe de saúde devem enfrentar, e que todos sofrem com ela. Segundo este autor, nesta experiência os pais necessitam de uma pessoa que lhes dê apoio para expressar seu sofrimento e lhes ajude a enfrentar a realidade. FOND ${ }^{10}$ afirma ainda que, a enfermeira que ajuda os pais nessa situação pode influir de maneira significativa na forma em que eles continuarão a lidar com a realidade.

Acredito que não teria sido difícil para as enfermeiras da situação acima descrita, compartilhar seu próprio sofrimento pela morte de C. com o sofrimento do pai da criança, se existisse entre eles uma relação profunda de confiança. Penso que elas poderiam ter expressado seus próprios sentimentos por meio de choro, uma das formas através das quais eu própria expressei os meus.

MARLOW ${ }^{17}$ opina ser necessário que a enfermeira reconheça seus próprios sentimentos e inadequaçðes e que trabalhe suficientemente com eles para que possa dar cuidado efetivo, tanto à criança como a seus pais, particularmente quando enfrentam situação de morte. EPSTEIN ${ }^{6}$ afirma que a experiência profissional da enfermeira diminui muito devido à repressão ou negação de seus próprios sentimentos.

Chorar, segundo EPSTEIN", "é uma forma de comunicação, de demonstrar solidariedade, de se unir a outro ser humano para confortá-lo"; "solidarizar-se com os sentimentos de outrém", acrescenta a autora, "significa compartilhar esses sentimentos".

\section{CONCLUSÕES}

A análise das diferentes situaçð̃es que foram observadas permitiu chegar às seguintes conclusōes:

- as interaçð̃es que ocorrem entre enfermeiras e pais de crianças hospitalizadas são escassas e não efetivas;

- os pais envolvidos nas situaçðes analisadas não receberam da enfermeira 0 apoio e a ajuda que precisavam; e

- as enfermeiras que participaram nas situaçōes descritas tiveram dificuldades para interagir efetivamente com os pais devido a que não apresentaram uma atitude adequada e porque não utilizaram técnicas apropriadas ao se comunicarem com os pais.

Pelas conclusões acima, pode-se afirmar que nem todos os benefícios e 
vantagens, referidos no início deste trabalho, foram obtidos nas situaçōes estudadas, e que nem todas as enfermeiras de unidades pediátricas que apresentam sistema de internação conjunta estão preparadas para trabalhar com pais de crianças hospitalizadas.

NEIRA HUERTA, E. del P. Interactions between nurses and parents of hospitalized children. Rev. Esc. Enf. USP. São Paulo, 19(1): 81.93, 1985.

With the purpose of supplying subsidies to nurses who work in pediatric wards, and using observation as method, the author attempts to analise and comment the interactions that occur between nurses and parents of hospitalized children in different, but usual situations during the hospitalization of children.

\section{REFERÊNCIAS BIBLIOGRÁFICAS}

1. BARBOSA, L. T. Aspectos psico-sociais da ascistência à criança. Săo Paulo, Nestlé, Serviço de Informaçăo Científica, s.d. (Temas de Pediatria, 9).

2. BLAKE, F. et alii. Enfermería pediátrica. 8. ed., México, Interamerica, 1971.687 p.

3. BOWLBY, J. Cuidados maternos e saúde mental. Séo Paulo, Martins Fontes, 1981. 225 p.

4. BRIGHT, F. Parental anxiety - a barrier to communication. In: AMERICAN NURSE'S ASSOCIATION. Ana Clinical Sessions: 1966. New York, Appleton-Century-Crofts, 1966. p. 13-20.

5. The pediatric nurse and parental anxiety. Nurs. Forum, Hillsdale, 4(2): 30-47, May 1965.

6. EPSTEIN, C. Interaçio efetiva na enfermagem. Séo Paulo, E.P.U,, 1977.173 p.

7. EYRES, P. The role of the nurse in family-centered nursing. Nurs. Clin. North Amer. Philadelphia, 7(1): 27-39, Mar. 1972.

8. FAGIN, C. M. Pediatric rooming-in: its meaning for the nurse. Nurs Clin. North Amer., Philadelphia, 1(1): 83-93, Mar. 1966.

9. Why not involve parents when children are hospitalized? Amer. J. Nurs, New York, 62(6): 78-79, June 1962.

10. FOND, K. I. Dealing with dead and dying through family-centered care. Nurs. Clin. North Amer., Philadelphia, 7(1): 53-64, Mar. 1972.

11. FREIBERG, K. How parents react when their child is hospitalized. Amer. J. Nurs, New York, 72(7): 1270-72, July 1972.

12. HARDGROVE, C. RUTLEDGE, A. Parenting during hospitalization. Amer. J. Nurs, New York, 75(5): 836-38, May 1975.

13. HARRIS, P. J. How parents feel. Nurs. Times, London, 77(42): 1803-04, Oct. 1981.

14. Mac CARTHY, D. The under fives in hospital. Nurs. Times, London, 77(30; suppl): 22-28, July 1981.

15. MAHAFFY, P. Admissions interviews with parents. Amer. J. Nurs., New York, 66(3): 506-8, Mar. 1966.

16. Nurse-parent relationships in living-in situations. Nurs, Forum, Hillsdale, 3(2): 53-68, May 1964.

17. MARLOW, D. Textbook of pediatric nursing 5. ed., Philadelphia, Saunders, 1977.949 p.

18. MORAES, E. \& PAULA, M. A. de Como percebi a ineficiência do ensino de enfermagem pediátrica no aspecto referente à assistência aos pais. Rev. Esc. Enf. USP, ST̃o Paulo, 14(3): 243-56, dez. 1980. 
19. NOLAN, H. Hospitalization of infants and pre-schoolers-observations and reflections of by a live-in mother. Lamp, Sidney, 38(8): 29-35, Aug. 1981.

20. PRUGH, D. et alii. A study of the emotional reactions of children and families to hospitalization and illness. Amer. J. Orthopsychiatry, New York, 23(1): 70-106, Jan. 1953.

21. ROBERTSON, J. Some responses of young children to the loss of maternal care. Nurs. Times, London, 49(16): 382-86, Apr. 1953.

22. ROY, C. Role cues for the mother of the hospitalized child. In: AMERICAN NURSE'S ASSOCIATION. Ans Cinical Sessions: 1968. New York, Appleton-Century-Crofts, 1968. p. 199206.

23. SCOFIELD, C. Parents in the hospital. Nurs. Clin. North Amer., Philadelphia, 4(1):59-67, Mar. 1969.

24. VAN DER SHYFF, G. The role of parents during their child hospitalization. Austral. Nurs. J., Port Adelaide, 8(11): 57-61, June 1979.

25. VERMILLION, B. et alii. The effective use of parent care unit for infants on the surgical service. J. Pediat. Surg., New York, 14(3): 321-24, June 1979.

26. WHALEY, L. F. \& WONG, D. L. Essentials of pediatric nursing Saint Louis, Mosby, 1982. $943 \mathrm{p}$.

27. WOFFINDIM, K. E. Children and their parents in hospital. Nurs. Times, London, 77(suppl; 8): 31-32, Mar. 1981. 